\title{
Feasibility and effects of adapted cardiac rehabilitation after stroke: a prospective trial
}

\author{
Ada Tang1,2,3, Susan Marzolini2,3, Paul Oh3,4, William E Mcllroy2,3,4,5 and Dina Brooks*1,2,3,4
}

\begin{abstract}
Background: Despite the cardiovascular etiology of stroke, exercise and risk factor modification programs akin to cardiac rehabilitation (CR) are not available. This study aimed to establish the feasibility of adapting a CR model for individuals with mild to moderate stroke disability. A secondary objective was to determine the program's effects on aerobic and walking capacity, and stroke risk factors.

Methods: A repeated measures design was used with a 3-month baseline period and 6-month adapted CR intervention ( $n=43$, mean \pm SD age $65 \pm 12$ years, $30 \pm 28$ months post stroke). Feasibility was determined by the number of participants who completed the study, occurrence of adverse events and frequency, duration and intensity of exercise performed. To determine effectiveness of the program, outcomes measured included aerobic capacity ( $\mathrm{VO}_{2}$ peak, ventilatory threshold), 6-Minute Walk Test (6MWT) distance, and risk factors. Descriptive statistics characterized the classes attended and number and intensity of exercise sessions. Paired $t$-tests, one-factor repeated measures analyses of variance contrasts and chi-square analyses were used to compare changes over time.
\end{abstract}

Results: Two participants withdrew during the baseline period. Of the remaining 41 participants who commenced the program, 38 (93\%) completed all aspects. No serious adverse effects occurred. Post-intervention, $\mathrm{VO}_{2}$ peak improved relative to the stable baseline period $(P=0.046)$ and the increase in ventilatory threshold approached significance $(P=$ 0.062).

Conclusions: CR is feasible after stroke and may be adapted to accommodate for those with a range of post-stroke disability. It is effective in increasing aerobic capacity. CR may be an untapped opportunity for stroke survivors to access programs of exercise and risk factor modification to lower future event risk.

Trial registration: ClinicalTrials.gov registration number: NCT01067495

\section{Background}

Stroke is the leading cause of neurological disability in adults [1]. Poor levels of fitness, including low aerobic capacity [2] can compound the challenges by further limiting the ability to engage in many daily activities and impacting risk of subsequent stroke. Traditional stroke rehabilitation is effective in improving functional independence [3] yet insufficiently challenges the cardiorespiratory system to induce aerobic benefit [4].

In contrast, cardiac rehabilitation (CR) is focused on exercise and risk factor management and is part of routine care for individuals with cardiac disease. Similar programs are lacking for the stroke population. Parallels

* Correspondence: dina.brooks@utoronto.ca

1 Department of Physical Therapy, University of Toronto, Toronto, Canada Full list of author information is available at the end of the article between stroke and heart disease in cardiovascular etiology, co-morbidities and risk factors suggest that a CR model of care may provide stroke survivors much-needed health promotion opportunities for secondary prevention.

A key challenge remains in the adaptability of traditional CR to accommodate participants with moderate levels of disability from stroke. Neurological deficits commonly impact on the ability to engage in exercise such as walking, and alternative modes of aerobic training (e.g. stationary cycling) must be considered. Appropriate staff training and conducting classes with lower staff-to-participant ratios [5] may accommodate for stroke-related issues such as cognitive or communication impairment, issues not typically encountered in traditional CR. 
Therefore, the primary objective was to establish the feasibility of an adapted CR model of care with stroke survivors with mild to moderate impairment. The secondary objective was to determine the effects of this rehabilitation model on aerobic and walking capacity, and stroke risk factors.

\section{Methods}

The study was conducted as part of an outpatient CR program in a rehabilitation facility. Study procedures were approved by local university and hospital research ethics committees. Informed written consent was obtained from all participants. A repeated-measures design was used with a 3-month monitoring period without intervention, followed by a 6-month adapted $\mathrm{CR}$ program (Figure 1).

\section{Participants}

Individuals at least 3 months post-stroke were recruited from stroke rehabilitation programs, outpatient followup clinics and from the community, and were eligible if they were able to provide informed consent, understand the evaluation procedures, walk more than 10 meters independently with or without aids and have a ChedokeMcMaster Stroke Assessment [6] leg impairment score of 3 (marked spasticity and weakness) or higher (representing less impairment) at the start of the program. Exclusion criteria included contraindications to maximal exercise testing [7], or significant musculoskeletal, pain, cognitive or behavioural issues that would limit the ability to perform the exercise testing and/or participate in the program.

\section{Intervention}

The adapted CR, conducted at the Toronto Rehabilitation Institute's Cardiac Rehabilitation and Secondary Prevention Program, was modeled after its traditional program [8]: once-weekly 90-minute sessions of education and supervised, individually-prescribed aerobic and resistance exercise training were supplemented by 4 addi- tional aerobic and 1-2 additional resistance training sessions conducted at home. All training sessions were tracked via weekly exercise diaries. The 1:5 staff-to-participant ratio used in the adapted model was lower than the usual 1:12 ratio, and class size of 20 participants was lower than the typical 80-100 [8]. These adaptations permitted adequate supervision yet facilitated progressively greater independence over time.

Aerobic exercise was prescribed 5 days per week. Initial training intensity was established based on a combination of first calculating $60-80 \%$ of heart rate reserve (HRR) [9], which was then compared to the heart rate at the ventilatory anaerobic threshold (VAT) [10] to ensure agreement between these methods. Finally, the intensity of exercise may have been adjusted to achieve an 11-14 rating of perceived exertion (RPE) [11]. For this adapted program, heart rate, rather than $\mathrm{VO}_{2}$, was used to guide training intensity as oxygen requirements for various activities are significantly higher for those with physical impairments compared to non-impaired individuals; individuals poststroke may need to expend up to 2 times more energy than people without stroke walking at the same pace [12].

Aerobic exercise progressed up to 30-60 minutes per session. Exercise intensity was monitored using the final HR (via 10-second pulse rate taken at the radial artery or HR monitor) and RPE taken at the end of the training session. The weekly average training HR was calculated from the final HR values recorded on the exercise diaries.

Training modality was individually prescribed. Over ground walking was preferred and was typical of the traditional CR program. Walking was prescribed if ambulation capacity was at sufficiently high speeds and duration to accrue aerobic benefit. The program was adapted to use upright and semi-recumbent cycle ergometers when stroke-related balance deficits and lower limb dys-control precluded walking programs [13]. Other adaptations included the use of interval training (short bouts of higher exercise intensity performed between longer periods of lower intensity exercise) for those unable to sustain

\begin{tabular}{|c|c|c|c|c|}
\hline \multirow{3}{*}{ Time } & \multicolumn{2}{|c|}{ 3-month Baseline Period } & \multicolumn{2}{|c|}{ 6-month Adapted Cardiac Rehabilitation Program } \\
\hline & -3 months & $0 \mathrm{mo}$ & ths & 6 months \\
\hline & $\uparrow$ & 1 & & $\uparrow$ \\
\hline Measures & $\begin{array}{l}\text { Aerobic capacity } \\
\text { Five-meter walk } \\
\text { Six-Minute Walk Test } \\
\text { Stroke Impact Scale }\end{array}$ & $\begin{array}{r}\text { Aerobic } \\
\text { Five-me } \\
\text { Six-Minute } \\
\text { Stroke Imr } \\
\text { Risk factc }\end{array}$ & $\begin{array}{l}\text { apacity } \\
\text { er walk } \\
\text { Walk Test } \\
\text { act Scale } \\
\text { profiles }\end{array}$ & $\begin{array}{l}\text { Aerobic capacity } \\
\text { Five-meter walk } \\
\text { Six-Minute Walk Test } \\
\text { Stroke Impact Scale } \\
\text { Risk factor profiles }\end{array}$ \\
\hline
\end{tabular}


faster walking or cycling pace for prolonged periods $(\mathrm{n}=$ 5), or dividing exercise across 2 sessions within the same day if initial tolerance was low. On the exercise diaries, total exercise time and final training HR were recorded, regardless of the method of training.

Resistance training was prescribed 2-3 sessions per week for 7-10 upper and lower body exercises. Initial weight loads of $60 \%$ of 1-repetition maximum were used for the non-paretic limb. For the paretic limb, a necessary adaptation was use of the rating of perceived exertion (11-14) rather than 1-repetition maximum to guide intensity. One set of 10 repetitions was prescribed initially, and participants progressed to 2 sets and increased to 15 repetitions before weights increased. Resistance was provided through hand held dumbbells, resistance bands, body weight or weight machines. Assessment of functional abilities, degree of hypertonicity, available range of motion and severity of balance impairment were considered.

Education sessions were held 1-2 times monthly and included many topics standard to the traditional CR stream (heart-healthy diet, diabetes management, or blood pressure (BP) control). Other sessions were specifically designed or adapted for the stroke participants, including sleep apnea and stroke risk or considerations for purchasing home exercise equipment after stroke.

\section{Measures \\ A. Feasibility}

Feasibility was determined by the number of participants who completed the study, occurrence of adverse events and frequency, duration and intensity of exercise as recorded on weekly diaries. As a conservative estimate, if a diary was not submitted, it was assumed that no exercise was performed that week.

At the end of the study, participants' satisfaction with the program was evaluated by asking, on a scale of 1 (Poor) to 5 (Excellent), "Please rate the following components of the program: 1) aerobic exercise sessions, 2) strength exercise sessions and 3) education sessions".

Other outcome measures were completed at 3 possible time points: 1) start of the baseline period (Pre-Baseline, 3 months), 2) end of the baseline and start of intervention (Pre-Program, 0 months) and 3) end of the intervention (Post-Program, 6 months) (Figure 1).

\section{B. Aerobic capacity}

A symptom-limited graded maximal exercise test determined peak oxygen uptake $\left(\mathrm{VO}_{2}\right.$ peak), peak work rate and VAT. Resting HR and BP were also noted.

Ten (23\%) of the 43 participants were deemed 'higher risk' because of cardiac history or presence of cardiovascular symptoms (e.g. myocardial infarction, angina, dysrhythmias), thus were tested at the CR cardiopulmonary assessment laboratory [8]. Of these 10 participants, 6 were tested using an upright cycle ergometer, 3 with a recumbent cycle ergometer and 1 using a modified Bruce treadmill protocol [14]. The 33 (77\%) remaining participants were tested in the stroke research laboratory using a semi-recumbent cycle ergometer. The protocol was based on one used previously [13], modified to use 5-, 10- or 15-watt incremental increases in work rate to maintain total test time between 8-10 minutes. VAT, defined as the point where ventilation increases at a greater rate than oxygen uptake [15], was determined graphically [10] using 2 independent assessors.

\section{Six-minute walk test (6MWT)}

Standardized instructions [16] were given to walk as far as possible over a 30-meter course in 6 minutes. Gait aids were permitted. A practice trial was performed before the actual test [17]. The distance covered was the primary outcome. Distance was also expressed as a percentage of predicted values based on age, sex, weight and height [18].

\section{Cardiovascular disease risk factor profiles}

Resting BP was measured at all 3 time points as part of the maximal exercise test. Measurement of waist and hip circumference, percent body fat by bioelectrical impedance analysis, fasting blood glucose, glycated haemoglobin, total, high- (HDL) and lowdensity lipoprotein (LDL) cholesterol and triglyceride levels were made at pre- and post-intervention only as these assessments were part of routine practice in the traditional CR program. Participants who met the criteria for the metabolic syndrome [19] were identified.

\section{Analysis}

A sample size of 27 was chosen based on calculations to detect a clinically important difference of 54 meters in the $6 \mathrm{MWT}$ among individuals with chronic obstructive pulmonary disease [20] (two-tailed type I error 0.05 , type II error $90 \%$, SD 96). To account for attrition and to provide an opportunity to detect changes in other primary outcomes, we aimed to recruit over 30 participants.

Descriptive statistics were performed on participants' baseline characteristics, classes attended, number and intensity of exercise sessions completed, and on all measures at each available time point. To determine differences over time for continuous variables, paired $t$-tests (change from 0 to 6 months) or one-factor repeated measures analyses of variance contrasts (change over baseline period ( -3 to 0 months), and from baseline ( $-3,0$ months) to the end of the program (6 months)) were used. Chisquare analyses compared changes over time for noncontinuous variables. Statistical Analysis Software Version 9.1 was used with a significance level of $P<0.05$. 


\section{Results}

Study sample

Figure 2 depicts the flow of recruitment, enrolment and study completion. Forty-three participants enrolled (Table 1). After the first test (Pre-Baseline, -3 months), 2 participants were removed from further analysis (medical issues unrelated to study, loss to follow up) (Figure 2). The remaining 41 participants demonstrated no changes in the primary outcome measures over the baseline period $(P=0.09-0.98)$, and all commenced the adapted CR program.

While participants' stroke severity was primarily mild according to the National Institutes of Health stroke scale [21] (29 (71\%) mild, 12 (29\%) moderate, 0 severe), mobility-related outcomes described otherwise. Participants walked $56 \%$ of predicted $6 \mathrm{MWT}$ distance [18], 17 (42\%) were classified as household or limited community ambulators based on gait speed [22], and 11 (27\%) presented with severe gait asymmetry [23].

\section{Feasibility of adapted CR after stroke}

Of the 41 people who started the adapted CR program, 38 (93\%) completed the study (Figure 2). Three participants withdrew due to the following: transportation issue; medical issue unrelated to study; inability to schedule final study assessments.

Two medical events occurred during the course of the study that temporarily affected program participation: 1) flare-up of chronic hip bursitis managed with stretching and adapting exercises to minimize pain and inflammation, and 2) onset of low-back and hip pain managed with postural education and modifying aerobic training to stationary cycling instead of walking. Both issues resolved and the exercise programs were completed without interruption.

Aerobic exercise prescriptions progressed from an initial $20.1 \pm 6.9$ minutes of exercise per session to $28 \pm 10.2$ minutes by the end of the program $(P<0.0001)$. Walking was prescribed for 26 people (over ground walking $n=$ 25 , treadmill $n=1$ ), 11 used cycle ergometry and 1 person had a combination program of walking and cycling. Participants in the cycle ergometry group had lower Chedoke-McMaster Stroke Assessment leg scores compared to the other groups $(4.4 \pm 1.3$ vs. $5.5 \pm 1.3, P=0.03)$.

Class attendance was $83.5 \pm 11.5 \%$, with 31 (82\%) participants attending $\geq 75 \%$ of classes. According to the 76.6 $\pm 19.6 \%$ of diaries submitted, participants exercised a median of 4 (range $0-7$ ) aerobic sessions (76 \pm 52 minutes) per week, at an intensity of $48.9 \pm 23.2 \%$ (range 0 $92 \%)$ of HRR. This represented $63 \pm 28.2 \%$ of exercise time prescribed.

In response to the post-program satisfaction survey (n = 34), median (range) ratings for the aerobic training,
Table 1: Participant characteristics

\begin{tabular}{|c|c|}
\hline Variable & n (\%) or mean \pm SD (range) \\
\hline Men & $30(70 \%)$ \\
\hline Age, years & $64.5 \pm 12.2(38-86)$ \\
\hline Time post-stroke, months & $30 \pm 27.3(3-113)$ \\
\hline $\begin{array}{l}\text { Ischemic/Hemorrhagic/ } \\
\text { Unknown stroke type }\end{array}$ & $27(63 \%) / 11(26 \%) / 5(12 \%)$ \\
\hline $\begin{array}{l}\text { Right/Left/Bilateral } \\
\text { hemisphere affected }\end{array}$ & $17(40 \%) / 24(56 \%) / 2(5 \%)$ \\
\hline \multicolumn{2}{|l|}{ Cardiovascular history } \\
\hline $\begin{array}{l}\text { Prior stroke/ } \\
\text { transient ischemic } \\
\text { attack }\end{array}$ & $5(12 \%) / 2(5 \%)$ \\
\hline Atrial fibrillation & $7(16 \%)$ \\
\hline $\begin{array}{l}\text { Myocardial } \\
\text { infarction }\end{array}$ & $1(2 \%)$ \\
\hline $\begin{array}{l}\text { Left ventricular } \\
\text { hypertrophy }\end{array}$ & $1(2 \%)$ \\
\hline $\begin{array}{l}\text { Coronary artery } \\
\text { bypass graft surgery }\end{array}$ & $4(9 \%)$ \\
\hline $\begin{array}{l}\text { Percutaneous } \\
\text { coronary } \\
\text { intervention }\end{array}$ & $1(2 \%)$ \\
\hline Diabetes & $12(28 \%)$ \\
\hline Hypertension & $28(65 \%)$ \\
\hline Dyslipidemia & $34(79 \%)$ \\
\hline $\begin{array}{l}\text { Never smoked/Remote } \\
\text { smoker/Currently } \\
\text { smoking }\end{array}$ & $29(67 \%) / 9(21 \%) / 5$ (12\%) \\
\hline $\begin{array}{l}\text { Gait aids, None/Cane/ } \\
\text { Walker/Rollator }\end{array}$ & $17(40 \%) / 18(42 \%) / 1(2 \%) / 7(16 \%)$ \\
\hline $\begin{array}{l}\text { National Institutes of } \\
\text { Health stroke scale score }\end{array}$ & $2.9 \pm 2.7(0-11)$ \\
\hline \multicolumn{2}{|l|}{$\begin{array}{l}\text { Chedoke-McMaster } \\
\text { Stroke Assessment scores }\end{array}$} \\
\hline Arm/Hand & $4.4 \pm 1.6(2-7) / 4.6 \pm 1.8(2-7)$ \\
\hline Leg/Foot & $5.1 \pm 1.3(2-7) / 4.4 \pm 1.7(2-7)$ \\
\hline Berg Balance Scale score & $46.4 \pm 11.6(4-56)$ \\
\hline \multicolumn{2}{|l|}{ 5-Meter Walk } \\
\hline $\begin{array}{l}\text { Self-paced gait } \\
\text { speed, } \mathrm{cm} / \mathrm{s}\end{array}$ & $76.8 \pm 35.5(20.4-152.3)$ \\
\hline $\begin{array}{l}\text { Fast-paced gait } \\
\text { speed, } \mathrm{cm} / \mathrm{s}\end{array}$ & $85.2 \pm 37.4(28.3-169.7)$ \\
\hline $\begin{array}{l}\text { Calculated gait } \\
\text { symmetry ratio, self- } \\
\text { paced walk }\end{array}$ & $1.50 \pm 0.6(1.01-3.85)$ \\
\hline $\begin{array}{l}\text { Calculated gait } \\
\text { symmetry ratio, fast- } \\
\text { paced walk }\end{array}$ & $1.49 \pm 0.49(1.02-2.63)$ \\
\hline
\end{tabular}

Baseline characteristics for all participants, $n=43$ 


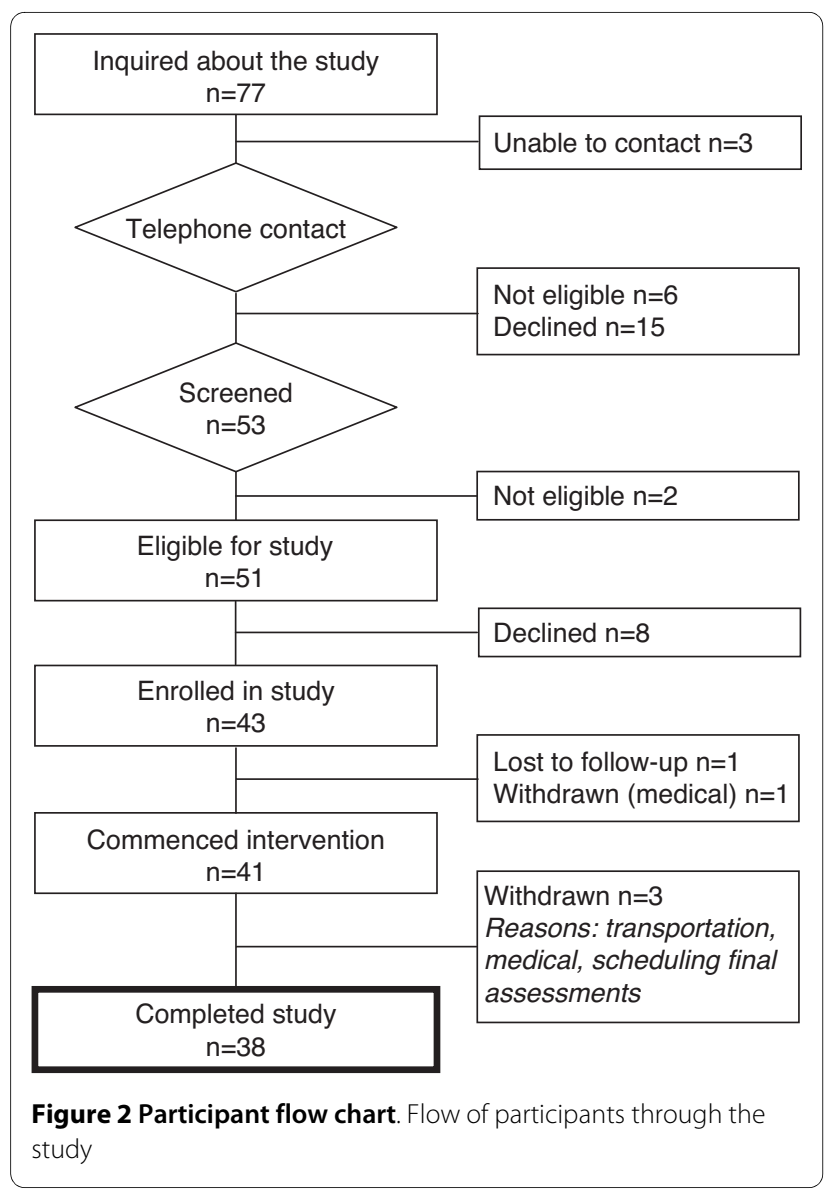

resistance training and education sessions were 5 (1-5), 5 (1-5) and 5 (2-5) respectively.

\section{Effect of adapted CR on aerobic and walking capacity, and risk factors}

$\mathrm{VO}_{2}$ peak improved significantly at end of the CR program relative to the baseline period $(P=0.046)$ and the increase in VAT approached significance $(P=0.062)$ (Table 2, Figure 3 ). Post hoc analyses comparing change scores in $\mathrm{VO}_{2}$ peak and VAT among participant groups who trained aerobically through walking versus cycling did not reveal any significant results $\left(\mathrm{VO}_{2}\right.$ peak change among cyclers $(\mathrm{n}=11)$ vs. walkers $(\mathrm{n}=27$, including the participant who trained via walking and cycling) 1.5 and $1.4 \mathrm{ml} \cdot \mathrm{kg}^{-1} \cdot \mathrm{min}^{-1}$ respectively $(P=0.91)$, VAT change 1.8 and $1.5 \mathrm{ml} \cdot \mathrm{kg}^{-1} \cdot \mathrm{min}^{-1}$ respectively $\left.(P=0.96)\right)$.

While statistically non-significant, average change in $6 \mathrm{MWT}$ distance from -3 to 0 months was 2.2 meters, and the change from 0 to 6 months was 24.6 meters (Table 2, Figure 3). Secondary subgroup analysis conducted to determine group differences based on training modality did not reveal any significant results (change 21 vs. 24 meters for cyclers and walkers respectively, $\mathrm{P}=0.20$ ).
There were no post-program changes in risk factors (Table 3), although slight reductions in percent body fat (change $0.3 \%$ ) and fasting plasma glucose (change 0.24 $\mathrm{mmol} / \mathrm{L}$ ) were observed. Two participants who initially met the criteria for the metabolic syndrome no longer did so by the end of the study.

\section{Discussion}

The important finding from this study is that a CR model of exercise and risk factor management is feasible after stroke, providing that appropriate adaptations are made to accommodate for participants with mild to moderate disability. In addition, consistent with more targeted, stroke-specific aerobic training programs, adapted CR is effective in improving cardiorespiratory fitness.

Results from the current study support the adaptation of $\mathrm{CR}$ to include individuals with a range of mobility restrictions post-stroke. $\mathrm{CR}$ is a well-established program of care for individuals with cardiac conditions that is effective in reducing mortality [24,25], improving lipid profiles, BP [24] and fitness [26]. Stroke and heart disease share cardiovascular etiologies and risk factors, yet the availability of analogous secondary prevention programs are lacking in stroke care. Stroke survivors have little opportunity for fitness-based pursuits in traditional facilities [27] and CR programs that may include individuals with stroke, do so in a limited manner [5].

While baseline neurological indices characterized the study sample as mild to moderate in stroke severity, mobility assessments revealed that ambulatory capacity was considerably compromised. To accommodate the range of walking abilities among participants, adaptations in training modality and higher staffing ratios were employed. Utilizing alternatives for exercise testing and training (e.g. recumbent cycle ergometry) permitted individuals with limited ambulatory capacity to participate. Smaller class size and lower staff-to-participant ratio provided an adequate balance between close supervision, guidance, and encouragement to become more independent over time for the stroke participants. We observed low attrition and adverse event rates, and high levels of class attendance and participant satisfaction. Indeed the rate of program completion (93\%) observed in the current study is higher than the $50-70 \%$ cited in the CR literature $[28,29]$.

The adapted CR program, conducted in a community rehabilitation setting with a single on-site group format session, led to improvement in aerobic capacity over time. Pre-program fitness levels were below the metabolic energy requirements needed to perform many ADL's [30], but did exceed the $15 \mathrm{ml} \cdot \mathrm{kg}^{-1} \cdot \mathrm{min}^{-1}$ threshold [31] by program completion. The mean change in $\mathrm{VO}_{2}$ peak was lower than overall average change of 3.5 $\mathrm{ml} \cdot \mathrm{kg}^{-1} \cdot \mathrm{min}^{-1}$ reported in a recent Cochrane review that 


\begin{tabular}{|c|c|c|c|c|c|c|}
\hline & \multirow[b]{2}{*}{$\mathbf{n}$} & \multirow[b]{2}{*}{$\begin{array}{l}\text { Pre-Baseline-3 } \\
\text { months }\end{array}$} & \multirow[b]{2}{*}{$\begin{array}{l}\text { Pre-Program } 0 \\
\text { months }\end{array}$} & \multirow[b]{2}{*}{$\begin{array}{l}\text { Post-Program } 6 \\
\text { months }\end{array}$} & \multicolumn{2}{|c|}{$P$ values } \\
\hline & & & & & $\begin{array}{l}\text { ANOVA contrast } \\
\text { for Pre-Baseline } \\
\text { (-3 months) vs. } \\
\text { Pre-Program } \\
\text { (0 months) }\end{array}$ & $\begin{array}{l}\text { ANOVA contrast } \\
\text { for Baseline Period } \\
\text { (-3, } 0 \text { months) vs. } \\
\text { Post-Program } \\
\text { (6 months) }\end{array}$ \\
\hline \multicolumn{7}{|l|}{ Aerobic capacity } \\
\hline $\mathrm{VO}_{2}$ peak, $\mathrm{ml} \cdot \mathrm{kg}^{-1} \cdot \mathrm{min}^{-1}$ & 32 & $\begin{array}{l}13.6 \pm 4.1 \\
(5.8-22.7)\end{array}$ & $\begin{array}{l}14.8 \pm 4.8 \\
(7-24.5)\end{array}$ & $\begin{array}{l}16.2 \pm 5.1 \\
(7.4-27.9)\end{array}$ & 0.301 & 0.046 \\
\hline Peak workload, watts & 36 & $\begin{array}{l}60.4 \pm 27.8 \\
(15-120)\end{array}$ & $\begin{array}{c}63.1 \pm 31.2 \\
(20-130)\end{array}$ & $\begin{array}{l}64.6 \pm 33.2 \\
(20-130)\end{array}$ & 0.709 & 0.647 \\
\hline $\begin{array}{l}\text { Ventilatory anaerobic threshold, } \\
\mathrm{ml} \cdot \mathrm{kg}^{-1} \cdot \mathrm{min}^{-1}\end{array}$ & 27 & $\begin{array}{l}10.3 \pm 2.7 \\
(4.8-14.9)\end{array}$ & $\begin{array}{c}11 \pm 3.2 \\
(5.9-19.5)\end{array}$ & $\begin{array}{l}11.9 \pm 3.0 \\
(6.1-18.5)\end{array}$ & 0.335 & 0.062 \\
\hline Resting heart rate, beats/minute & 38 & $\begin{array}{c}73.9 \pm 13.8 \\
(50-106)\end{array}$ & $\begin{array}{l}73.4 \pm 12.5 \\
(52-103)\end{array}$ & $\begin{array}{l}71.6 \pm 14.8 \\
(44-102)\end{array}$ & 0.877 & 0.459 \\
\hline \multicolumn{7}{|l|}{ Resting blood pressure } \\
\hline Systolic, mmHg & 38 & $\begin{array}{l}121 \pm 13.7 \\
(100-170)\end{array}$ & $\begin{array}{l}122.6 \pm 15.7 \\
(89-158)\end{array}$ & $\begin{array}{l}122.8 \pm 17.3 \\
(93-184)\end{array}$ & 0.66 & 0.74 \\
\hline Diastolic, mmHg & 38 & $\begin{array}{l}76.4 \pm 11.4 \\
(54-94)\end{array}$ & $\begin{array}{l}74.8 \pm 10.9 \\
(52-98)\end{array}$ & $\begin{array}{l}77.3 \pm 10 \\
(41-100)\end{array}$ & 0.51 & 0.431 \\
\hline \multicolumn{7}{|l|}{ Walking capacity } \\
\hline 6MWT distance, meters & 37 & $\begin{array}{l}284.2 \pm 145.8 \\
\quad(30-547)\end{array}$ & $\begin{array}{l}286.4 \pm 140 \\
(45-576)\end{array}$ & $\begin{array}{l}311 \pm 152.1 \\
(55-585)\end{array}$ & 0.948 & 0.382 \\
\hline
\end{tabular}

Changes in study outcomes across 3 time points: pre-baseline (-3 months), and pre- and post-program (0, 6 months)

Values are mean \pm SD (range). Abbreviations: $6 \mathrm{MWT}=6$-Minute Walk Test; $\mathrm{SIS}=$ Stroke Impact Scale.

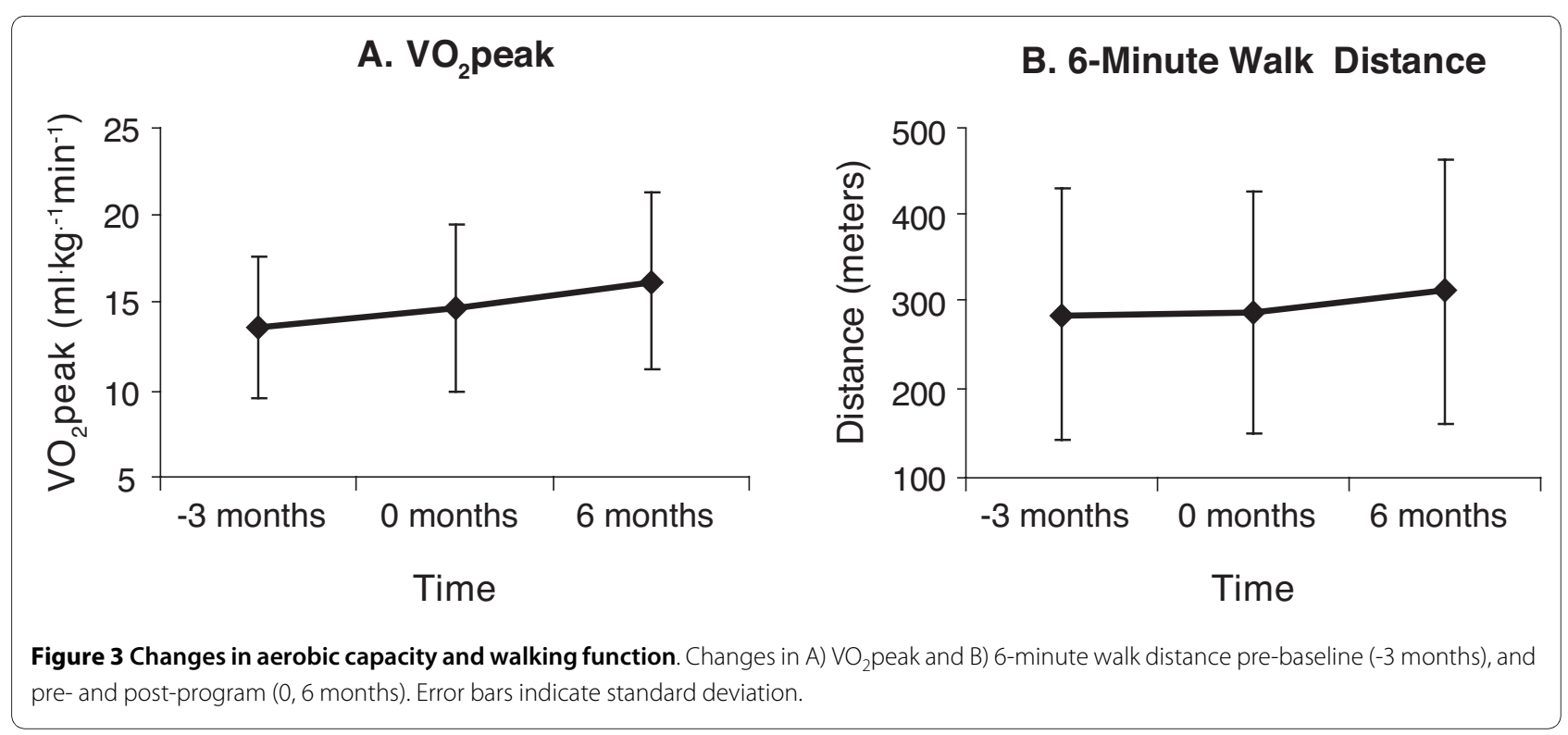


Table 3: Changes in study outcomes measured at 2 time points

\begin{tabular}{lcccc}
\hline & $\mathbf{n}$ & Pre-Program 0 months & Post-Program 6 months & $\begin{array}{c}\text { P values for Pre-Baseline (0 } \\
\text { months) vs. Post-Program (6 } \\
\text { months) }\end{array}$ \\
& & & & \\
\hline Body composition & & & & 0.72 \\
Waist circumference, centimeters & 34 & $97.5 \pm 15.5(70-126)$ & $97.2 \pm 13.4(74-125)$ & 0.59 \\
Hip circumference, centimeters & 34 & $103.9 \pm 10.4(79-126)$ & $103.6 \pm 9.8(81-126)$ & 0.88 \\
Waist-hip ratio & 34 & $0.94 \pm 0.1(0.77-1.26)$ & $0.94 \pm 0.1(0.78-1.08)$ & 0.27 \\
Body fat, \% & 32 & $28.1 \pm 8.7(9.7-47)$ & $27.8 \pm 8.6(10.3-49.7)$ & 0.48 \\
Lipid profiles & & & & 0.96 \\
LDL cholesterol, mmol/L & 27 & $2.38 \pm 0.7(1.3-3.8)$ & $2.38 \pm 0.7(1.2-3.7)$ & 0.60 \\
HDL cholesterol, mmol/L & 27 & $1.27 \pm 0.3(0.78-1.83)$ & $1.31 \pm 0.3(0.91-2.0)$ & 0.26 \\
Total-HDL cholesterol ratio & 27 & $3.84 \pm 0.8(2.1-5.6)$ & $3.76 \pm 1.0(2.2-5.7)$ & $1.37 \pm 0.7(0.4-3.2)$ \\
Triglycerides & 27 & $1.34 \pm 0.8(0.5-4.2)$ & & 0.35 \\
Glucose and glucose control & & & $5.55 \pm 1.0(4-8)$ & 0.71 \\
Blood glucose, mmol/L & 28 & $5.79 \pm 1.1(4.4-9.4)$ & $5.94 \pm 0.7(4.9-7.5)$ & 0.18 \\
Glycated hemoglobin, \% & 28 & $5.88 \pm 0.7(4.8-8.2)$ & $10(39 \%)$ & \\
Metabolic syndrome, $\mathrm{n}$ & 26 & & & \\
\hline
\end{tabular}

Changes in study outcomes across 2 time points: pre-program ( 0 months) to post-program (6 months)

Values are $\mathrm{n}(\%)$ or mean $\pm \mathrm{SD}$ (range). Abbreviations: $\mathrm{HDL}=$ high-density lipoprotein; $\mathrm{LDL}=$ low-density lipoprotein.

combined the results of randomized controlled exercise trials for individuals with stroke [32]. The magnitude of change was, however, comparable to other non-CR exercise interventions that may have used study methodologies other than randomized controlled trials that relied on multiple weekly on-site exercise sessions [13,33-35]. Macko and colleagues [35] demonstrated improvements in $\mathrm{VO}_{2}$ peak and $6 \mathrm{MWT}$ distance with aerobic treadmill training but these sessions were not conducted in a group format. Group classes, such as an 8-week water-based exercise [36] and a 19-week fitness and mobility exercise program [37] increased post-stroke aerobic capacity by $23 \%$ [36] and $9 \%$ [37] and 6MWT performance by $65 \%$ [37] but, in both of these trials, interventions were comprised of 3 on-site exercise sessions per week and did not include any home-based component. The benefits of 10 weeks of supervised versus unsupervised exercise programs after stroke was examined in another study, and comparable effects were observed in both groups with respect to $6 \mathrm{MWT}$ performance $(11 \%$ and $17 \%$ improvement in the supervised and unsupervised groups, respectively) and self-reported physical health [38]. While progressive aerobic exercise was a major component of this intervention, cardiorespiratory fitness was not explicitly measured [38]. Only one pilot study has specifically examined the use of a CR model after stroke, where the 10-week intervention of twice weekly on-site sessions and supervision at a 1:2 staff-to-participant ratio resulted in benefits to aerobic capacity and cardiac risk [39]. A full-scale trial has been proposed [40].

It should be noted that the change in $\mathrm{VO}_{2}$ peak observed across the baseline period (change $1.2 \mathrm{ml} \cdot \mathrm{kg}^{-}$ 1. $\mathrm{min}^{-1}$ ) was only slightly lower than the magnitude of pre- to post-program change (change $1.4 \mathrm{ml} \cdot \mathrm{kg}^{-1} \cdot \mathrm{min}^{-1}$ ), raising into question the true effectiveness of the intervention on aerobic capacity if there was improvement during the baseline observation period. Issues with measurement error or test-retest reliability of the maximal exercise tests in the stroke population may offer a partial explanation, but a wide range in intraclass correlations have been reported for repeated maximal exercise testing among individuals with stroke [41-43]. It is not known if a portion of the change in $\mathrm{VO}_{2}$ peak observed during the baseline period in the current study may be attributed to a practice effect, as only 1 trial of the maximal exercise test was conducted. The high variation in individual participant responses in $\mathrm{VO}_{2}$ peak across the 3 different time points may also explain why the changes observed across the baseline period were not statistically significant. Given this large variation, future study using a larger sample size may provide insight into the true effects of this adapted CR program.

There are important advantages to adapting the existing CR model to stroke. Most important is the opportunity to provide programs to these individuals using existing infrastructure and expertise in cardiovascular 
risk factor management through education and exercise [44]. In addition, CR has well-established approaches to maximize the 'at home' component of training that optimizes benefits but limits resource demands (versus a model of multiple weekly on-site training sessions). In the current study, we observed a successful combination of both on-site and at-home exercise sessions for a broad range of participants. Improvement in aerobic capacity is a key finding considering $80 \%$ of exercise sessions were unsupervised. Training intensity was lower than the intended target of $60-80 \%$ of HRR, although it has been suggested that lower intensity exercise (as low as $40 \%$ of HRR) may be sufficient to derive aerobic benefit among those with stroke $[2,45]$.

The increase in aerobic capacity did not translate to improvements in functional ambulation as hypothesized. The variability of $6 \mathrm{MWT}$ performance may partially account for the lack of significant findings. However, more importantly, the CR program strove to improve cardiorespiratory capacity with no structured components to improve neuromotor control. Previous studies focused on post-stroke aerobic training have also revealed little benefit to neuromotor control $[13,46]$. Future research may delineate specific training that concurrently addresses cardiorespiratory fitness and walking ability after stroke.

Post-program changes in risk factors did not reach significance but, as noted, participants did demonstrate slight reductions in percent body fat and fasting plasma glucose. In addition, 2 participants no longer met the criteria for the metabolic syndrome by the end of the study. In an earlier study, improvements in indices of insulin sensitivity have been demonstrated with aerobic treadmill training after stroke but changes in fasting glucose were not observed [47]. Rimmer and colleagues [48] reported improvements in resting BP and total cholesterol particularly with moderate intensity short duration aerobic exercise after stroke; triglyceride levels were reduced with moderate intensity short duration and low intensity long duration exercise. Lennon et al [40] reported improvement in overall cardiac risk score after $\mathrm{CR}$ intervention with stroke, but not in the individual risk score components. The changes observed in the current study are encouraging given the small sample size; further study is warranted with a larger participant pool sufficiently powered to determine if a CR model may mediate risk for recurrent stroke.

There are several limitations to this study. As this study used a single cohort design, one limitation is the lack of control group. While not a considerable limiting issue for the purpose of establishing feasibility of the adapted CR program, future study to further establish effectiveness of this model of care would benefit from an independent control group. With regards to the exercise diaries, the conservative estimate used in assuming that " 0 " minutes of exercise was performed if a diary was not submitted may have underestimated the actual amount completed. As well, the variance in $6 \mathrm{MWT}$ scores was unexpectedly higher than what was used for calculation of sample size. Thus, we were likely underpowered to detect changes in this outcome, in addition to changes in stroke risk factors as previously mentioned. Further, changes in muscular strength and endurance and thus the role of resistance training on study outcomes are not described here. Finally, analysis of follow-up data to determine if the observed benefits were retained after the program ended is also warranted.

\section{Implications}

There is currently a dearth of opportunities for stroke survivors to receive guidance on safe and effective exercise to lower recurrent stroke risk. CR may be an innovative opportunity to translate a successful and wellestablished model of care across both sides of cardiovascular disease management. The applicability of $\mathrm{CR}$ to stroke stems from the commonalities between stroke and heart disease. Given the cardiovascular etiology of stroke and presence of shared co-morbidities and risk factors, a CR model of care may fill this gap in stroke care. This study is an important first step in designing effective long-term community-based secondary stroke prevention programs. We demonstrated that CR may be feasibly adapted to accommodate for individuals with a wide range of functional abilities post-stroke and is effective in increasing aerobic capacity.

\section{Conclusions}

In summary, a CR model of care may offer communitybased exercise and education programming for risk factor management and can be adapted to accommodate individuals with mild to moderate stroke disability. Despite using only once weekly, supervised exercise sessions supplemented with 4 sessions of independent at-home exercise per week, this adapted program is effective in increasing aerobic capacity. CR may be an untapped opportunity for stroke survivors to access programs of exercise and risk factor management.

\section{Competing interests}

The authors declare that they have no competing interests.

\section{Authors' contributions}

AT, as primary author, participated in study design, was responsible for writing the manuscript, data collection, analysis and interpretation. SM participated in data collection and analysis and interpretation. PO participated in study design, assisted with medical screening and data collection and interpretation. WEM conceived of the study, assisted with data analysis and interpretation. DB conceived of the study, assisted with data analysis and helped draft the manuscript. All authors have read and approved the final manuscript. 


\section{Acknowledgements}

Supported by the Heart and Stroke Foundation of Ontario (Grant \#SRA5977). DB is a Canada Research Chair, AT was supported by the Heart and Stroke Foundation of Canada, Canadian Institutes of Health Research, Canadian Stroke Network, Government of Ontario/Heart and Stroke Foundation of Ontario, Toronto Rehabilitation Institute, Physiotherapy Foundation of Canada and the University of Toronto, SM was supported by the University of Toronto. We acknowledge the support of the Heart and Stroke Foundation of Ontario, and the Toronto Rehabilitation Institute who receives funding under the Provincial Rehabilitation Research Program from the Ministry of Health and Long Term Care in Ontario.

We would like to thank D Barry-Hickey, M Bayley, K Dobson, C Ford, D Richardson and $\mathrm{M}$ Strong for their assistance and support.

\section{Author Details}

'Department of Physical Therapy, University of Toronto, Toronto, Canada, IInstitute of Medical Science, University of Toronto, Toronto, Canada, ${ }^{3}$ Toronto Rehabilitation Institute, Toronto, Canada, ${ }^{4}$ Heart and Stroke Foundation of Ontario Centre for Stroke Recovery, Sunnybrook Health Sciences Centre, Toronto, Canada and ${ }^{5}$ Department of Kinesiology, Faculty of Applied Health Sciences, University of Waterloo, Waterloo, Canada

Received: 4 January 2010 Accepted: 9 June 2010

Published: 9 June 2010

\section{References}

1. American Heart Association: 2002 Heart and Stroke statistical update. 2002.

2. Pang MYC, Eng JJ, Dawson AS, Gylfadottir S: The use of aerobic exercise training in improving aerobic capacity in individuals with stroke: a meta-analysis. Clin Rehabil 2006, 20:97-111.

3. Jorgenson HS, Nakayama H, Raaschou HO, Vive-Larsen J, Stoier M, Olsen TS: Outcome and time course of recovery in stroke. Part II: time course of recovery. The Copenhagen stroke study. Arch Phys Med Rehabil 1995, 76:406-412.

4. MacKay-Lyons MJ, Makrides L: Cardiovascular stress during a contemporary stroke rehabilitation program: Is the intensity adequate to induce a training effect? Arch Phys Med Rehabil 2002, 83:1378-1383.

5. Tang A, Closson V, Marzolini S, Oh P, Mcllroy WE, Brooks D: Cardiac rehabilitation after stroke: need and opportunity. Journal of Cardiopulmonary Rehabilitation and Prevention 2009, 29(2):97-104.

6. Gowland C, Van Hullenaar S, Torresin WD, Moreland J, Vanspall B, Barecca S, Ward M, Huijbregts MP, Stratford P, Barclay-Goddard R: ChedokeMcMaster Stroke Assessment: development, validation and administration manual. Hamilton: Chedoke-McMaster Hospitals and McMaster University; 1995.

7. American College of Sports Medicine: ACSM's guidelines for exercise testing and prescription. Philadelphia: Lippincott Williams \& Wilkins; 2006.

8. Hamm L, Kavanagh T: The Toronto Cardiac Rehabilitation and Secondary Prevention Program: 1968 into the new millennium. $J$ Cardiopulm Rehabil 2000, 20(1):16-22.

9. Karvonen MJ, Kentala JE, Mustala O: The effects of training on heart rate. Ann Med Exp Biol Fenn 1957, 35:307-315.

10. American Thoracic Society/American College of Chest Physicians: ATS/ ACCP statement of cardiopulmonary exercise testing. American Journal of Respiratory and Critical Care Medicine 2003, 167(2):211-277.

11. Borg G: Perceived exertion as an indicator of somatic stress. Scand J Rehabil Med 1970, 2:92-98

12. Fredrickson E, Ruff RL, Daly JJ: Physiological cost index as a proxy measure for the oxygen cost of gait in stroke patients. Neurorehabil Neural Repair 2007, 21:429-434.

13. Tang A, Sibley KM, Thomas SG, Bayley MT, Richardson D, Mcllroy WE, Brooks D: Effects of an aerobic exercise program on aerobic capacity, spatiotemporal gait parameters, and functional capacity in subacute stroke. Neurorehabil Neural Repair 2009, 23(4):398-406.

14. Bruce R, Kusumi F, D H: Maximal oxygen intake and nomographic assessment of functional aerobic impairment in cardiovascular disease. Am Heart J 1973, 85(4):546-562

15. Cunningham DA, Nancekievill EA, Paterson DH, Donner AP, Rechnitzer PA: Ventilation threshold and aging. J Geronto/ 1985, 40(6):703-707.
16. American Thoracic Society: ATS statement: guidelines for the six-minute walk test. American Journal of Respiratory and Critical Care Medicine 2002, 166(1):111-117.

17. Solway S, Brooks D, Lacasse $Y$, Thomas SG: A qualitative systematic review of the measurement properties of functional walk tests used in the cardiorespiratory domain. Chest 2001, 119:256-270.

18. Enright PL, Sherrill DL: Reference equations for the Six-Minute Walk in healthy adults. American Journal of Respiratory and Critical Care Medicine 1998, 158:1384-1387.

19. National Cholesterol Education Program Expert Panel on Detection Evaluation and Treatment of High Blood Cholesterol in Adults (Adult Treatment Panel III): Third report of the National Cholesterol Education Program Expert Panel on Detection Evaluation and Treatment of High Blood Cholesterol in Adults (Adult Treatment Panel III) Final report. Circulation 2001, 106(25):3143-3421.

20. Redelmeier DA, Bayoumi AM, Goldstein RS, Guyatt GH: Interpreting small differences in functional status: the Six Minute Walk test in chronic lung disease patients. American Journal of Respiratory and Critical Care Medicine 1997, 155(4):1278-1282.

21. Brott T, Adams HP, Olinger CP, Marler JR, Barson WG, Biller J, Spilker J, Helleran R, Eberle R, Hertznerg V, Rorick M, Moomaw CJ, Walker M: Measurements of acute cerebral infarction: a clinical examination scale. Stroke 1989, 20(7):864-870.

22. Bowden MG, Balasubramanian CK, Behrman AL, Kautz SA: Validation of a speed-based classification system using quantitative measures of walking performance poststroke. Neurorehabil Neural Repair 2008, 22(6):672-675

23. Patterson KK, Parafianowicz I, Danells CJ, Closson V, Verrier MC, Staines WR, Black SE, Mcllroy WE: Gait asymmetry in community-ambulating stroke survivors. Arch Phys Med Rehabil 2008, 89(2):304-310

24. Taylor RS, Brown A, Ebrahim S, Jolliffe J, Noorani H, Rees K, Skidmore B, Stone JA, Thompson DR, Oldridge N: Exercise-based rehabilitation for patients with coronary heart disease: systematic review and metaanalysis of randomized controlled trials. Am J Med 2004 116(10):682-692.

25. Alter $\mathrm{D}, \mathrm{Oh} \mathrm{Pl}, \mathrm{Chong} \mathrm{A}$ : Relationship between cardiac rehabilitation and survival after acute cardiac hospitalization within a universal health care system. European Journal of Cardiovascular Prevention and Rehabilitation 2009, 16(1):102-113.

26. Belardinelli R, Paolini I, Cianci G, Piva R, Georgiou D, Purcaro A: Exercise training intervention after coronary angioplasty: the ETICA trial. J Am Coll Cardiol 2001, 37(7):1891-1900.

27. Fullerton A, Macdonald M, Brown A, Ho P, Martin J, Tang A, Sibley KM, Mcllroy WE, Brooks D: Survey of fitness facilities for individuals poststroke in the Greater Toronto Area. Applied Physiology, Nutrition, and Metabolism 2008, 33(4):713-719.

28. Marzolini S, Brooks D, Oh Pl: Sex differences in completion of a 12month cardiac rehabilitation programme: an analysis of 5922 women and men. Eur J Cardiovasc Prev Rehabil 2008, 15(6):698-703.

29. Cannistra LB, Balady GJ, O'Malley CJ, Weiner DA, Ryan TJ: Comparison of the clinical profile and outcome of women and men in cardiac rehabilitation. Am J Cardiol 1992, 69(16):1274-1279.

30. Rimmer JH, Wang E: Aerobic exercise training in stroke survivors. Topics in Stroke Rehabilitation 2005, 12(1):17-30.

31. MacKay-Lyons MJ, Makrides L: Exercise capacity early after stroke. Arch Phys Med Rehabil 2002, 83:1697-1702.

32. Saunders DH, Greig CA, Mead GE, Young A: Physical fitness training for stroke patients (Cochrane Review). The Cochrane Database of Systematic Reviews 2009:CD003316.

33. Duncan PW, Studenski S, Richards L, Gollub S, Lai SM, Reker D, Perera S, Yates J, Koch V, Rigler S, Johnson D: Randomized clinical trial of therapeutic exercise in subacute stroke. Stroke 2003, 34:2173-2180.

34. Rimmer JH, Riley B, Creviston T, Nicola T: Exercise training in a predominantly African-American group of stroke survivors. Med Sci Sports Exerc 2000, 32(12):1990-1996.

35. Macko RF, Ivey FM, Forrester LW, Hanley D, Sorkin JD, Katzel LI, Silver KH, Goldberg AP: Treadmill exercise rehabilitation improves ambulatory function and cardiovascular fitness in patients with chronic stroke. Stroke 2005, 36:2206-2211.

36. Chu KS, Eng JJ, Dawson AS, Harris JE, Ozkaplan A, Gylfadottir S: Waterbased exercise for cardiovascular fitness in people with chronic stroke: a randomized controlled trial. Arch Phys Med Rehabil 2004, 85:870-874. 
37. Pang MYC, Eng JJ, Dawson AS, McKay HA, Harris JE: A community-based fitness and mobility exercise (FAME) program for older adults with chronic stroke: a randomized controlled trial. J Am Geriatr Soc 2005, 53:1667-1674.

38. Olney SJ, Nymark J, Brouwer B, Culham E, Day A, Heard J, Henderson M, Parvataneni K: A randomized controlled trial of supervised versus unsupervised exercise programs for ambulatory stroke survivors. Stroke 2006, 37:476-481.

39. Lennon O, Carey A, Gaffney N, Stephenson J: A pilot randomized controlled trial to evaluate the benefit of the cardiac rehabilitation paradigm for the non-acute ischaemic stroke population. Clin Rehabil 2008, 22:125-133.

40. Lennon O, Blake C: Cardiac rehabilitation adapted to transient ischaemic attack and stroke (CRAFTS): a randomized controlled trial. BMC Neurology 2009, 9:9.

41. Eng JJ, Dawson AS, Chu KS: Submaximal exercise in persons with stroke: test-retest reliability and concurrent validity with maximal oxygen consumption. Arch Phys Med Rehabil 2004, 85:113-118.

42. Dobrovolny CL, Ivey FM, Rogers MA, Sorkin JD, Macko RF: Reliability of treadmill exercise testing in older patients with chronic hemiparetic stroke. Arch Phys Med Rehabil 2003, 84(9):1308-1312.

43. Tang A, Sibley KM, Thomas SG, Mcllroy WE, Brooks D: Maximal exercise test results in sub-acute stroke. Arch Phys Med Rehabil 2006, 87:1100-1105.

44. Canadian Association of Cardiac Rehabilitation: Canadian guidelines for cardiac rehabilitation and cardiovascular disease prevention. Edited by: Anonymous Winnipeg. Canadian Association of Cardiac Rehabilitation; 2004.

45. Gordon NF, Gulanick M, Costa F, Fletcher G, Franklin BA, Roth EJ, Shephard T: Physical activity and exercise recommendations for stroke survivors. Stroke 2004, 35(5):1230-1240.

46. Kautz SA, Duncan PW, Perera S, Neptune RR, Studenski SA: Coordination of hemiparetic locomotion after stroke rehabilitation. Neurorehabil Neural Repair 2005, 19(3):250-258.

47. Ivey FM, Ryan AS, Hafer-Macko CE, Goldberg AP, Macko RF: Treadmill aerobic training improves glucose tolerance and indices of insulin sensitivity in disabled stroke survivors. Stroke 2007, 38:2752-2758.

48. Rimmer JH, Rauworth AE, Wang EC, Nicola TL, Hill B: A preliminary study to examine the effects of aerobic and therapeutic (nonaerobic) exercise on cardiorespiratory fitness and coronary risk reduction in stroke survivors. Arch Phys Med Rehabil 2009, 90(3):407-412.

\section{Pre-publication history}

The pre-publication history for this paper can be accessed here: http://www.biomedcentral.com/1471-2377/10/40/prepub

doi: $10.1186 / 1471-2377-10-40$

Cite this article as: Tang et al., Feasibility and effects of adapted cardiac rehabilitation after stroke: a prospective trial BMC Neurology 2010, 10:40 